\title{
The clinicopathological study of postmenopausal bleeding
}

\author{
Rita D.*, Sunil Kumar K.S., Rithesh S.K.
}

Department of Obstetrics and Gynecology, SDM Medical College, Dharwad, Karnataka, India

\author{
Received: 02 October 2016 \\ Revised: 15 October 2016 \\ Accepted: 17 October 2016 \\ *Correspondence: \\ Dr. Rita D., \\ E-mail: rita.vijayachandra@gmail.com
}

Copyright: (c) the author(s), publisher and licensee Medip Academy. This is an open-access article distributed under the terms of the Creative Commons Attribution Non-Commercial License, which permits unrestricted non-commercial use, distribution, and reproduction in any medium, provided the original work is properly cited.

\begin{abstract}
Background: Postmenopausal bleeding (PMB) represents one of the most common reasons for referral to gynaecological services, largely due to suspicion of an underlying endometrial malignancy.

Methods: The data was collected from 100 patients with postmenopausal bleeding per vaginum attending the outpatient department or admitted for evaluation under obstetrics and gynaecology in this prospective study. Written and informed consent was taken from all the patients enrolled in the study. They were evaluated by history, clinical examination and investigations like transvaginal sonography, endometrial biopsy, fractional curettage, Papanicolau smear done for all subjects and the specimens collected was sent to the department of pathology for examination and reporting. Descriptive statistics was applied and analyzed by percentages and chi square test.

Results: In patients with post-menopausal bleeding, atrophic endometrium was seen in $31 \%$, proliferative endometrium in $13 \%$, isthmic endometrium in $5 \%$, polyp in $5 \%$, simple hyperplasia without atypia in $35 \%$, simple hyperplasia with atypia in $3 \%$, complex hyperplasia without atypia in $1 \%$, complex hyperplasia with atypia in $1 \%$ and endometrial carcinoma in $6 \%$ of the patients with PMB. Benign conditions were seen in $94 \%$ and malignancy was seen in $6 \%$ cases.

Conclusions: The most common causes for postmenopausal bleeding were endometrial hyperplasia (40\%), atrophic endometrium (31\%), isthmic endometrium (5\%), polyp (5\%), proliferative endometrium (13\%) and endometrial carcinoma (6\%). A definitive diagnosis of PMB can be made by histological evaluation. Obesity, hypertension, diabetes mellitus and age since menopause are the risk factors for PMB.
\end{abstract}

Keywords: Endometrial hyperplasia, Endrometrium, Postmenopausal bleeding

\section{INTRODUCTION}

Postmenopausal bleeding (PMB) is not an uncommon clinical presentation in today's gynaecological practice. Contributory factors are perhaps increasing longevity, obesity and hormonal therapy which can be both supervised and unsupervised. Increasing number of women seeking help or reassurance for this problem due to increased awareness would also contribute to this increase. PMB occurs in approximately $10 \%$ of postmenopausal women. ${ }^{1}$
Bleeding from the genital tract occurring after the menopause is much more sinister than pre-menopausal bleeding. In the absence of hormonal therapy, any bleeding after menopause, should be promptly evaluated with endometrial sampling. ${ }^{2}$

As per a study on postmenopausal bleeding, the endometrium contributed to $50 \%$ of the causes. The findings were atrophic endometrium (16.3\%), endometrial hyperplasia (13.4\%), proliferative endometrium $(8.6 \%)$, endometrial polyp (2.8\%) and endometrial carcinoma $(9.6 \%){ }^{3}$ 
Therefore PMB requires complete assessment in order to ensure the absence of malignancy and to identify and treat high risk patients. Hence this study was undertaken to investigate the clinical significance and endometrial pathology in patients with postmenopausal bleeding.

\section{METHODS}

\section{Source of data}

The data was collected from patients with postmenopausal bleeding per vaginum attending the outpatient department or admitted for evaluation under obstetrics and gynaecology department, SDM College of medical sciences and hospital, Sattur, Dharwad from $1^{\text {st }}$ November 2013 to $1^{\text {st }}$ November 2014.

\section{Study design}

This study was a prospective study of the patients with postmenopausal bleeding attending the outpatient department or admitted for evaluation under obstetrics and gynaecology department at SDM College of medical sciences and hospital.

\section{Data collection}

Written and informed consent was taken from all the patients enrolled in the study. They were evaluated by history, clinical examination and investigations like transvaginal sonography, endometrial biopsy, fractional curettage, Papanicolau Smear and hysteroscopic guided biopsy if required was done for all subjects and the specimens collected was sent to the department of pathology for examination and reporting. Depending on the reports obtained, the data was recorded and analysed by descriptive statistics using percentages.

\section{Inclusion criteria}

Post-menopausal women with complaints of per vaginal bleeding.

\section{Exclusion criteria}

1. Patients with bleeding disorders / blood dyscrasias.

2. Patients on anticoagulant therapy.

The numbers of Sample size were 100.

Age group: Postmenopausal women

\section{Statistical analysis}

Descriptive statistics was applied and data was analysed by percentages and chi square test.

\section{RESULTS}

Majority i.e. $41 \%$ of the patients of PMB were in the age group of 50-54 years followed by $26 \%$ between $55-59$ years. $47 \%$ of the patients presenting with postmenopausal bleeding had attained menarche at 13 years followed by $31 \%$ at 12 years and $21 \%$ at 14 years. $59 \%$ of the patients with postmenopausal bleeding presented within 1-3 years after menopause followed by $12 \%$ between 4-6 years, 9\% between 7-9 years and $20 \%$ after 10 years of menopause. $19 \%$ of the patients presenting with postmenopausal bleeding had HTN, $6 \%$ had DM, 6\% had obesity, 4\% had HTN and DM, 3\% had HTN with DM and obesity and $2 \%$ had HTN and obesity.

Table 1: Distribution according to characteristics $(\mathrm{N}=\mathbf{1 0 0})$.

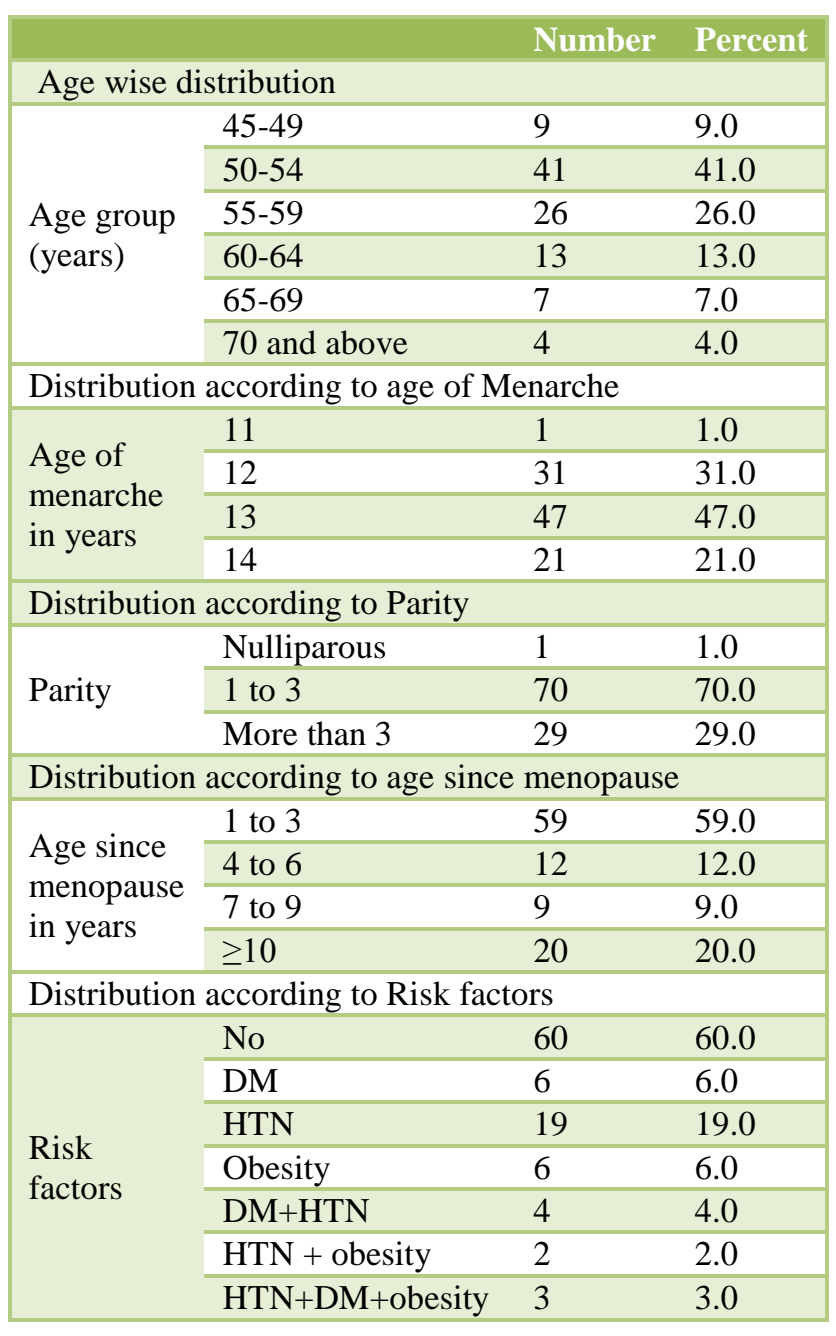

\section{DISCUSSION}

Postmenopausal bleeding is defined as any bleeding from the female genital tract in the appropriately aged woman, not using hormonal therapy for at least six months after cessation of menstruation or acyclical vaginal bleeding in a postmenopausal woman using hormonal therapy. ${ }^{4}$ 
Table 2: Distribution according to investigative procedures.

\begin{tabular}{|c|c|c|c|}
\hline \multicolumn{4}{|c|}{ Distribution according to PAP smear report } \\
\hline \multirow{5}{*}{$\begin{array}{l}\text { PAP smear } \\
\text { report }\end{array}$} & & Number & Percent \\
\hline & Not done & 9 & 9.0 \\
\hline & NILM & 41 & 41.0 \\
\hline & Inflammation & 26 & 26.0 \\
\hline & Atrophic & 13 & 13.0 \\
\hline \multicolumn{4}{|c|}{$\begin{array}{l}\text { Distribution according to TVS (endometrial thickness in } \\
\mathrm{mm} \text { ) }\end{array}$} \\
\hline \multirow{5}{*}{$\begin{array}{l}\text { TVS } \\
\text { (endometrial } \\
\text { thickness in } \\
\mathrm{mm} \text { ) }\end{array}$} & $1-5 \mathrm{~mm}$ & 52 & 52 \\
\hline & $6-10 \mathrm{~mm}$ & 38 & 38 \\
\hline & $11-15 \mathrm{~mm}$ & 5 & 5 \\
\hline & $16-20 \mathrm{~mm}$ & 4 & 4 \\
\hline & $>20 \mathrm{~mm}$ & 1 & 1 \\
\hline \multicolumn{4}{|c|}{ Distribution according to Endometrial sampling } \\
\hline \multirow{9}{*}{$\begin{array}{l}\text { Endometrial } \\
\text { sampling }\end{array}$} & Atrophic & 31 & 31 \\
\hline & Proliferative & 13 & 13 \\
\hline & Isthmic & 5 & 5 \\
\hline & Polyp & 5 & 5 \\
\hline & SHWOA & 35 & 35 \\
\hline & SHWA & 3 & 3 \\
\hline & CHWOA & 1 & 1 \\
\hline & CHWA & 1 & 1 \\
\hline & $\begin{array}{l}\text { Endometrial } \\
\text { carcinoma }\end{array}$ & 6 & 6 \\
\hline
\end{tabular}

Note SHWOA = Simple Hyperplasia without atypia; SHWA = Simple Hyperplasia with atypia; CHWOA = Complex hyperplasia without atypia; CHWA = Complex hyperplasia with atypia.

Postmenopausal women constitute only $1 \%$ of female population. PMB represents one of the most common reason for referral to gynaecological services, largely due to suspicion of an underlying endometrial malignancy. ${ }^{5} \mathrm{~A}$ woman not taking hormone replacement therapy (HRT), who bleeds after the menopause has a $10 \%$ risk of having genital cancer and a further $10 \%$ risk of significant pathology. ${ }^{6}$ This study was undertaken to investigate the clinical significance and endometrial pathology in patients with postmenopausal bleeding.

\section{Age of presentation}

In our study the most common age group of patients presenting with postmenopausal bleeding was between 51 to 55 years.

The results found in our study are in accordance with the above quoted studies.

\section{Age since menopause}

In our study the incidence of PMB from the time since menopause was most common within 1 to 3 years about $59 \%$. Similar results are found in our study.

\section{Parity}

In our study PMB was most commonly found in multiparous women. Similar results were found in other studies like, Kothapally et al where $90 \%$ were multiparous women and Nirupama $\mathrm{V}$ et al which also had $90 \%$ multiparous women presenting with postmenopausal bleeding. ${ }^{7,8}$

\section{Risk factors}

In a study done by Kothapally $\mathrm{K}$ et al it was observed that the risk factors for postmenopausal bleeding were obesity $(43.3 \%)$, diabetes $(36.6 \%)$ and hypertension $(13.3 \%){ }^{7}$ Similarly in a study by Nirupama V et al risk factors of the patients with PMB like obesity, hypertension and diabetes were $45 \%, 36 \%$ and $13 \%$ respectively. ${ }^{8}$

According to our study, $11 \%$ of the patients of PMB with HTN had SHWOA on HPE, 5\% had atrophic endometrium and $1 \%$ had endometrial carcinoma. $4 \%$ of the patients OF PMB with DM had atrophic endometrium and $1 \%$ had endometrial carcinoma. $1 \%$ of the patients of PMB with combined risk factors of HTN with DM and obesity had endometrial carcinoma. $3 \%$ of the patients of PMB with no risk factors had endometrial carcinoma.

\section{Transvaginal sonography}

In a study done by Kothapally $\mathrm{k}$ et al it was observed that women with a thick endometrial thickness $>4 \mathrm{~mm}$ are at risk of endometrial carcinoma. ${ }^{9}$ Kadakola $B$ et al observed that $34 \%$ of the patients with PMB had rophic endometrium with endometrial thickness $<4 \mathrm{~mm}$ and none had endometrial carcinoma. $14 \%$ of the patients with PMB had endometrial carcinoma with ET $>4 \mathrm{~mm}^{8}$

Table 3: Histopathological reports in comparison to other studies endometrial sampling.

\begin{tabular}{|lllll|}
\hline Atrophic & $\begin{array}{l}\text { Current } \\
\text { study }\end{array}$ & $\begin{array}{l}\text { Bharani } \\
\text { B et al }\end{array}$ & $\begin{array}{l}\text { Karmarkar } \\
\text { P et a }\end{array}$ & $\begin{array}{l}\text { Nirupama } \\
\text { V et al }\end{array}$ \\
\hline Proliferative & $13 \%$ & $16 \%$ & $32 \%$ & $11 \%$ \\
\hline Isthmic & $5 \%$ & - & $16.8 \%$ & - \\
\hline Polyp & $5 \%$ & - & - & - \\
\hline SHWOA & $35 \%$ & $56 \%$ & $21.2 \%$ & $8 \%$ \\
\hline SHWA & $3 \%$ & - & $7.2 \%$ & - \\
\hline CHWOA & $1 \%$ & $8 \%$ & - & $1 \%$ \\
\hline CHWA & $1 \%$ & $8 \%$ & - & - \\
\hline $\begin{array}{l}\text { Endometrial } \\
\text { carcinoma }\end{array}$ & $6 \%$ & $12 \%$ & $3.6 \%$ & $12 \%$ \\
\hline
\end{tabular}

SHWOA = Simple hyperplasia without atypia SHWA = Simple hyperplasia with atypia; CHWOA = Complex hyperplasia without atypia; CHWA = Complex hyperplasia with atypia

According to our study, $27 \%$ of the patients of PMB with endometrial thickness between 1-5 $\mathrm{mm}$ had atrophic endometrium, $14 \%$ had SHWOA and $2 \%$ had endometrial carcinoma. $18 \%$ of the patients of PMB with ET between 6-10 $\mathrm{mm}$ had SHWOA and $2 \%$ had 
endometrial carcinoma.1\% of the patients OF PMB with ET between 11-15 $\mathrm{mm}$ and 16-20 $\mathrm{mm}$ had endometrial carcinoma.

Pap smear shows that almost $26 \%$ of the patients presenting with PMB had NILM, 18\% had inflammation, $8 \%$ had atrophic smear. TVS ahoes that majority i.e. $52 \%$ of the patients with PMB had endometrial thickness between $1-5 \mathrm{~mm}$ followed by $38 \%$ between $6-10 \mathrm{~mm}$. HPE reports of the endometrial was found to be simple hyperplasia without atypia in $35 \%$, atrophic endometrium in $31 \%$ and proliferative endometrium in $13 \%$.

Table 4: Histopathological reports in comparison to other studies.

\begin{tabular}{|lllll|}
\hline $\begin{array}{l}\text { Endometrial } \\
\text { sampling }\end{array}$ & $\begin{array}{l}\text { Current } \\
\text { study }\end{array}$ & $\begin{array}{l}\text { Bharani } \\
\text { B et al }\end{array}{ }^{45}$ & $\begin{array}{l}\text { Karmarkar } \\
\text { P et al }\end{array}$ & $\begin{array}{l}\text { Nirupama } \\
\text { V et al }\end{array}$ \\
\hline Atrophic & $31 \%$ & $16 \%$ & $32 \%$ & $11 \%$ \\
\hline Proliferative & $13 \%$ & - & $16.8 \%$ & - \\
\hline Isthmic & $5 \%$ & - & - & - \\
\hline Polyp & $5 \%$ & - & $4 \%$ & $8 \%$ \\
\hline SHWOA & $35 \%$ & $56 \%$ & $21.2 \%$ & $17 \%$ \\
\hline SHWA & $3 \%$ & - & $7.2 \%$ & - \\
\hline CHWOA & $1 \%$ & $8 \%$ & - & $1 \%$ \\
\hline CHWA & $1 \%$ & $8 \%$ & - & - \\
\hline $\begin{array}{l}\text { Endometrial } \\
\text { carcinoma }\end{array}$ & $6 \%$ & $12 \%$ & $3.6 \%$ & $12 \%$ \\
\hline
\end{tabular}

SHWOA $=$ simple hyperplasia without atypia, $\mathrm{SHWA}=$ simple hyperplasia with atypia

$\mathrm{CHWOA}=$ complex hyperplasia without atypia, CHWA= complex hyperplasia with atypia

\section{CONCLUSION}

Patients with postmenopausal bleeding should be thoroughly evaluated for the various causes of PMB and mainly to rule out endometrial carcinoma.

Risks factors for PMB are age since menopause, obesity, hypertension and diabetes mellitus. A definitive diagnosis of PMB can be made by histological evaluation.

Bulky uterus on $\mathrm{P} / \mathrm{V}$ examination and endometrial thickness $>5 \mathrm{~mm}$ as per TVS should be further evaluated with endometrial sampling.

Most common causes for postmenopausal bleeding are endometrial hyperplasia (40\%), atrophic endometrium (31\%), isthmic endometrium (5\%), polyp (5\%), proliferative endometrium $(13 \%)$ and endometrial carcinoma $(6 \%)$.
Funding: No funding sources

Conflict of interest: None declared

Ethical approval: The study was approved by the Institutional Ethics Committee

\section{REFERENCES}

1. Rossouw JE, Anderson GL, Prentice RL. Risks and benefits of estrogen plus progestin in healthy postmenopausal women: principal results from the Women's Health Initiative randomized controlled trial. JAMA. 2002;288:321.

2. Bhatla N. Abnormal and excessive uterine bleeding. Jeffcoate. Principles of Gynaecology 5th edition. Jaypee Brothers Medical Publishers pvt ltd. 2001;578-9.

3. Adams Hillard PJ. Benign diseases of the female reproductive tract. Berek and Novak's Gynaecology 14th edition. Wolters Kluwer Health India pvt ltd. 2007;490-1.

4. Lidor A, Ismajovich B, Confino E, David MP. Histopathological findings in 226 women with postmenopausal uterine bleeding. Acta Obstet Gynecol Scand. 1986;65:41-3.

5. Hawwa ZM, Nahhas WA, Copenhaver EH. Postmenopausal bleeding. Lahey Clinic Foundation Bulletin. 1970;19:61-70.

6. Astrup K, Olivarius NDF. Frequency of spontaneously occurring postmenopausal bleeding in the general population. Acta Obstet Gynecol Scand. 2004;83:203-7.

7. Kadakola B, Gurushankar G, Shivamurthy G, Rashmi MN. Ultrasonographic evaluation of abnormal uterine bleeding in postmenopausal women. Int J Reprod Contracept Obstet Gynecol. 2015;4:229-34.

8. Nirupama V, Suneetha Y, Prabha Devi K. PostMenopausal Bleeding: An Analytic Study of 100 Cases. International Journal of Science and Research. 2015:4:2319.

9. Jillani K, Bahadur RK, Maqsood SA. M.S prevalence of malignant Disorder in 50 cases of postmenopausal bleeding. J. Pak Med Asso. 2010:60:540.

10. Kothapally K, Bhashyakarla U. Postmenopausal bleeding: clinicopathologic study in a teaching hospital of Andhra Pradesh: IntJ Reprod Contracept Obstet Gynecol. 2013;2(3):344-48.

Cite this article as: Rita D, Kumar SKS, Rithesh SK. The clinicopathological study of postmenopausal bleeding. Int J Reprod Contracept Obstet Gynecol 2016;5:3671-4. 